\title{
Emergency response technical work at Fukushima Dai-ichi nuclear power plant: occupational health challenges posed by the nuclear disaster
}

\author{
Koji Wada, ${ }^{1}$ Toru Yoshikawa, ${ }^{2}$ Takeshi Hayashi, ${ }^{3}$ Yoshiharu Aizawa ${ }^{4}$
}

${ }^{1}$ Department of Public Health, Kitasato University School of Medicine, Sagamihara, Japan ${ }^{2}$ Institute for Science of Labour, Kawasaki, Japan

${ }^{3}$ Hitachi Health Care Center, Hitachi, Japan

${ }^{4}$ Department of Preventive Medicine, Kitasato University

School of Medicine,

Sagamihara, Japan

\section{Correspondence to}

Dr Koji Wada, Junior Associate Professor, Department of Public Health, Kitasato University School of Medicine, 1-15-1 Kitasato, Minami-ku, Sagamihara, Kanagawa 252-0374, Japan;

kwada-sgy@umin.ac.jp

Published Online First 12 April 2012

This paper is freely available online under the BMJ Journals unlocked scheme, see http:// oem.bmj.com/site/about/ unlocked.xhtml

\section{INTRODUCTION}

Fukushima Dai-ichi nuclear power plant (NPP) was heavily damaged by the tsunami that resulted from the 9.0-magnitude earthquake which occurred off the coast of eastern Japan on 11 March 2011. ${ }^{1}$ The loss of all alternating current (AC) electrical power, even from emergency generators, disabled cooling functions and the supply of recycled water. Hydrogen explosions destroyed two reactor buildings and there was meltdown of the reactor cores. The nuclear accident was assigned the maximum severity level of 7 , which is equal to that of the Chernobyl disaster that occurred in $1986 .^{2}$

Efforts were made to achieve stable cooling of the nuclear reactors, and the release of radioactive materials was brought under control. On 16 December 2011, the Japanese government, the Tokyo Electric Power Company (TEPCO) and technical-support companies achieved cold shutdown of all the reactors stricken by the tsunami. During this period, numerous efforts were made to protect disaster response technical workers. The aim of this paper is to describe the greatly increased risk from hazards that disaster response technical workers faced because of the Fukushima Dai-ichi NPP disaster.

\section{TASKS OF THE JOB}

The tasks of disaster response technical workers in Fukushima Dai-ichi NPP after the tsunami were to restore the cooling of reactors and the fuel pools, containment and treatment of water contaminated by radioactive materials, and mitigation of radioactive materials emission in the environment eventually achieving the cold shutdown of the NPP. ${ }^{3}$ To achieve these objectives, radiation levels at the site were monitored to avoid any additional release of radioactive materials, and clean-up of rubble was implemented while ensuring the safety and health of workers. These tasks were part of a preliminary process towards the decommissioning of the Fukushima Dai-ichi nuclear power station which could take from 30 to 40 years.

In the early phase of the accident, the first priority was to minimise the risk of reactor explosion and restore the cooling system by ensuring electrical power that was achieved on March $26 .^{4}$ Reactor stabilisation and water decontamination became the next priority. Approximately 2000 to 3000 emergency response technical workers employed by TEPCO and technical-support companies were on the accident site daily until the end of year 2011. ${ }^{5}$ Women were not allowed to enter the plant after the accident.

\section{HAZARDS OF THE JOB AND THE WORKPLACE}

Hazards at the site varied as containment measures were put in place. However, there were four major hazards identified: radiation, heat, stress and machine operation and manual handling. Initially, potential hydrogen explosions and reactor meltdown causing high radiation exposure of the workers were the most serious hazards. As from May, heat exposure became an extremely important hazard because of the hot summer weather and workers having to work outdoors wearing double-layer Tyvek ${ }^{\circledR}$ protective coveralls and fullface respirators ${ }^{6}$ (figure 1) which inhibit evaporative cooling. Workers were exposed to multiple stressors, both work-related and personal. Workers were also at risk for injury from machine operation, manual clean-up of the tsunami rubble and stabilising the nuclear reactor for cold shutdown.

\section{Radiation}

After the explosion of reactor 1 on March 12, reactor 3 on March 14, reactor 4 on March 15 and the exposure of the fuel rods at reactor 2 , radioactive materials were released into the immediate environment and surrounding areas of Fukushima Dai-ichi NPP. The highest level of environmental exposure of radiation was recorded as $3130 \mu \mathrm{Sv} / \mathrm{h}$ at the monitoring post at the central gate of Fukushima Dai-ichi NPP. ${ }^{4}$ Table 1 shows the external, internal and total exposure of the workers to radiation from March to May 2011. In March, six workers received a high internal exposure of over $200 \mathrm{mSv}$ as measured by a whole-body counter. ${ }^{7}$ The maximum estimated exposure per worker was $670.4 \mathrm{mSv} .^{5}$ The workers subjected to such exposure may inhale radiation particles due to respirator leakage, or may not have worn respirators because of inaccurate exposure assessments or inadequate emergency operations. In March, not all workers possessed an alarm pocket dosimeter as many alarm pocket dosimeters were swept away by the tsunami. Instead, the leader of each operational group wore an alarm pocket dosimeter, and the external dose was estimated from exposure levels and time. Thus, for some workers, the external exposure levels for March and April (table 1) were estimated rather than actual values. ${ }^{5}$ However, as of 31 October 2011, a whole body counter was used to measure the internal exposure of all 17780 workers, except for 109 including 16 unidentified workers. In Fukushima Dai-ichi NPP, whole body counter testing was used for monitoring instead of the bioassay programme. 


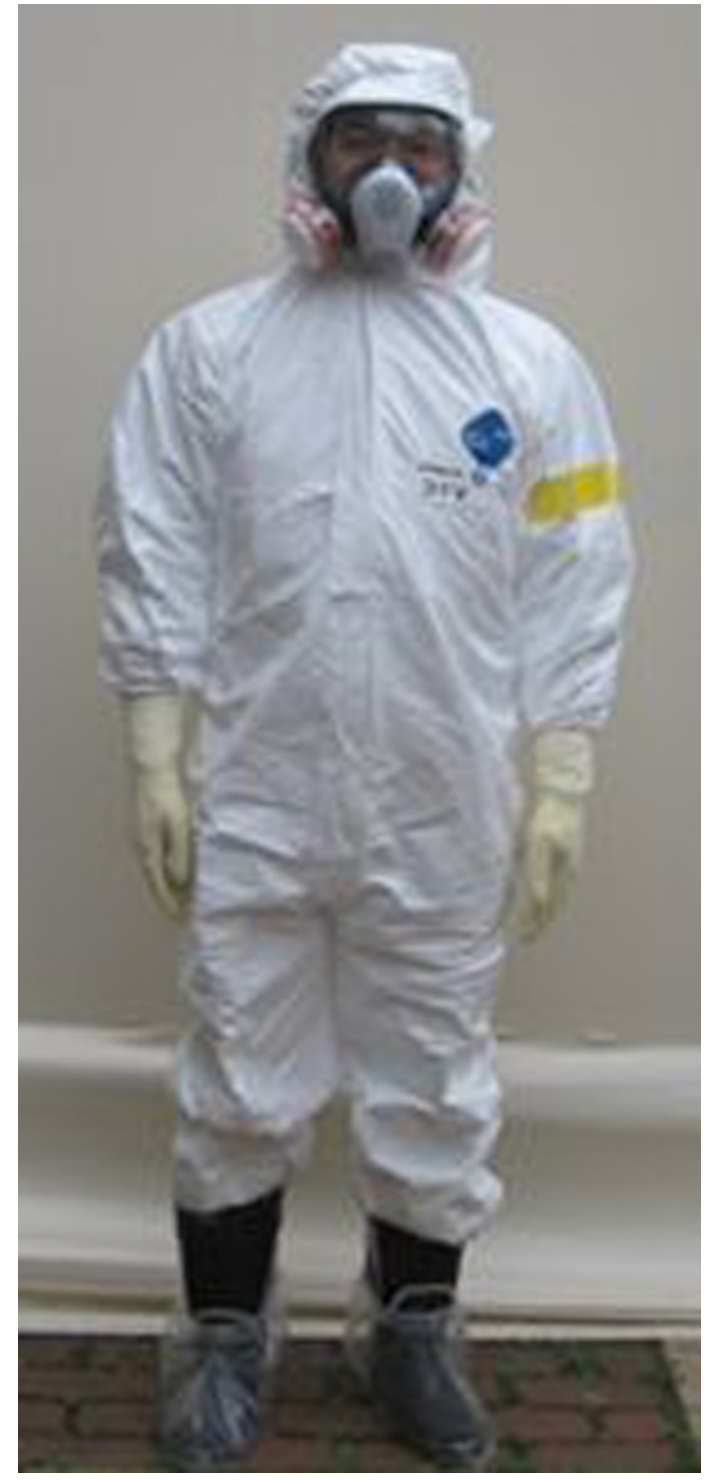

Figure 1 Workers at Fukushima Dai-ichi nuclear power plant wore double-layer Tyvek ${ }^{\circledR}$ protective coveralls, a tight-fitting full-face respirator with P100 filters, high boots covered by vinyl shoes, and cotton and rubber gloves.

The workers' exposure to radiation decreased as operations progressed, and the emission of iodine-131, one of the major radionuclides released and with a half-life of about 8 days, decayed to xenon-131 which is not radioactive. ${ }^{2}$ Consequently, in May, the cumulative exposure dose per month of all the workers did not exceed $50 \mathrm{mSv}$. Before the accident, the radiation exposure limit for workers in Japan was set at an effective dose of $50 \mathrm{mSv}$ per year and $100 \mathrm{mSv}$ over 5 years, based on the International Committee on Radiological Protection recommendations. On 14 March 2011, the government raised the effective dose limit from $100 \mathrm{mSv}$ to $250 \mathrm{mSv}$ in the event of an unavoidable emergency to ensure the number of technical and professional workers who could work on the site. ${ }^{8}$ On 16 December 2011, the Ministry of Health, Labour and Welfare in Japan reinstated the predisaster effective dose limit of $100 \mathrm{mSv}{ }^{8}$

In the Chernobyl disaster, 134 plant staff and emergency workers received high doses of radiation ranging from 0.8 to $16 \mathrm{~Gy}$ resulting in acute radiation syndrome, and 28 of them died within the first 4 months. ${ }^{9}$ In contrast, no workers have exhibited illness due to acute radiation syndrome in the Fukushima Dai-ichi NPP accident. Almost 99\% of the workers at Fukushima were exposed to a radiation dose of $<100 \mathrm{mSv}$ and the possibility of future adverse health effects is uncertain. ${ }^{9}$

\section{Heat}

The effect of ambient summer temperatures which often exceeded $28^{\circ} \mathrm{C}$ of the daytime wet bulb globe temperature from June to September in Fukushima Dai-ichi NPP, wearing doublelayer Tyvek ${ }^{\circledR}$ coveralls and full-face respirators, and the physical workload posed a high risk of heat stroke ${ }^{10}$ for all the workers at the nuclear power station. The American Conference of Governmental Industrial Hygienists screening criteria for heat-stress exposure assumes $8 \mathrm{~h}$ work days in a 5-day work week and requires a work to rest ratio of $75 \%$ rest and $25 \%$ work at $28.0^{\circ} \mathrm{C}$ for workers who are not acclimatised to heat, engaged in heavy labour and wearing lightweight clothing. The corrected exposure level for a worker wearing polyolefin coveralls is $+1^{\circ} \mathrm{C}$; however, the corrected exposure level for workers wearing clothing as thick as double-layer Tyvek ${ }^{\circledR}$ coveralls is not so easily assessed. $^{11}$

\section{Stress}

Workers were exposed to multiple stressors because of the accident. Workers feared additional explosions, exposure to high doses of radiation and successive aftershocks. In addition, most initial emergency responders settled in a $20 \mathrm{~km}$ radius of Fukushima Dai-ichi NPP, while the government forced their family and relatives to evacuate to other areas (figure 2). Some workers also lost their family and relatives because of the tsunami. Temporary accommodation for workers was set up

Table 1 Radiation exposure dose of workers at Fukushima Dai-ichi nuclear power plant, Japan, from March to May 2011

\begin{tabular}{|c|c|c|c|c|c|c|c|c|c|}
\hline & \multicolumn{3}{|l|}{ March } & \multicolumn{3}{|l|}{ April } & \multicolumn{3}{|l|}{ May } \\
\hline & $\begin{array}{l}\text { External } \\
\text { exposure }\end{array}$ & $\begin{array}{l}\text { Internal } \\
\text { exposure }\end{array}$ & $\begin{array}{l}\text { Total } \\
\text { exposure }\end{array}$ & $\begin{array}{l}\text { External } \\
\text { exposure }\end{array}$ & $\begin{array}{l}\text { Internal } \\
\text { exposure }\end{array}$ & $\begin{array}{l}\text { Total } \\
\text { exposure }\end{array}$ & $\begin{array}{l}\text { External } \\
\text { exposure }\end{array}$ & $\begin{array}{l}\text { Internal } \\
\text { exposure }\end{array}$ & $\begin{array}{l}\text { Total } \\
\text { exposure }\end{array}$ \\
\hline \multicolumn{10}{|l|}{ Radiation exposed(mSv) } \\
\hline$\geq 250$ & 0 & 5 & 6 & 0 & 0 & 0 & 0 & 0 & 0 \\
\hline $200-249$ & 0 & 1 & 2 & 0 & 0 & 0 & 0 & 0 & 0 \\
\hline $150-199$ & 9 & 1 & 14 & 0 & 0 & 0 & 0 & 0 & 0 \\
\hline $100-149$ & 28 & 5 & 77 & 0 & 0 & 0 & 0 & 0 & 0 \\
\hline $50-99$ & 163 & 78 & 309 & 2 & 0 & 3 & 0 & 0 & 0 \\
\hline $20-49$ & 421 & 260 & 859 & 56 & 1 & 81 & 18 & 0 & 19 \\
\hline $10-19$ & 883 & 666 & 1041 & 276 & 19 & 310 & 131 & 1 & 144 \\
\hline$<10$ & 2241 & 2726 & 1434 & 3286 & 3588 & 3214 & 2881 & 3016 & 2854 \\
\hline Total & 3745 & 3742 & 3742 & 3620 & 3608 & 3608 & 3030 & 3017 & 3017 \\
\hline Maximum exposure (mSv) & 199.4 & 590.0 & 670.4 & 65.9 & 41.8 & 69.3 & 41.6 & 10.1 & 41.6 \\
\hline
\end{tabular}




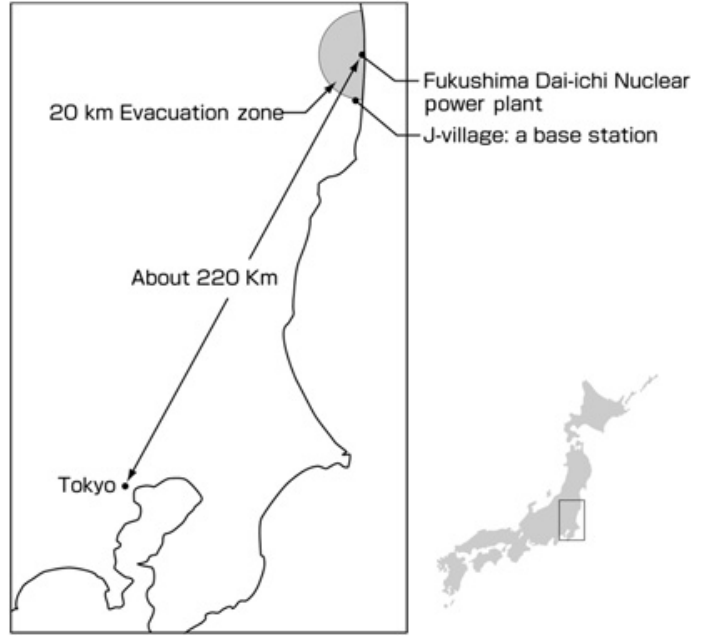

Figure 2 Map of Fukushima Dai-ichi nuclear power plant and J-village.

outside the evacuation area at a public gymnastic hall with poor living conditions. Living conditions for workers was not improved proactively because TEPCO also forced people in the surrounding areas to move to the evacuation centres which were also with poor living conditions. The number of technical and professional workers at Fukushima Dai-ichi NPP was limited and consequently they tended to work long hours.

\section{Machine operation and manual handling}

The first response to the disaster was to ensure AC power to stabilise the power plant. Thereafter, the removal of rubble and procedures for cold shutdown were implemented through machine operation and manual handling, which both posed risks for injury. Several mild and moderate injuries required referral to secondary or tertiary healthcare institutions. However, no fatal injuries had been reported as of 31 December 2011.

\section{MEASURES TO PROTECT WORKERS Radiation}

Shortly after the accident, J-village, a soccer training facility located $20 \mathrm{~km}$ south of Fukushima Dai-ichi NPP, was utilised as a place for preparing workers for entry into the nuclear power station, where they put on their protective equipment and performed decontamination tests when leaving (figure 2). Accommodation facilities for workers were set up outside the $20 \mathrm{~km}$ evacuation zone. Inside the Fukushima Dai-ichi NPP, the main earthquake-proof building, in which radiation exposure was controlled by a high-quality purified-air ventilation system, was set up as a direct command centre for operations and had some rooms for workers to stay overnight.

Several measures were taken to prevent external and internal radiation exposure. To minimise external exposure, the radiation level was assessed over the whole site, and workers monitored radiation exposure using an alarm pocket dosimeter. To protect workers from internal radiation exposure from inhaling radioactive particles and gas, workers wore a tight-fitting full-face respirator with $\mathrm{P} 100$ filters (figure 1). To minimise skin contamination, workers wore double-layer (to guard against tears during operations) Tyvek ${ }^{\circledR}$ protective coveralls, double gloves (inner cotton and outer rubber) and safety shoes covered by vinyl shoes. This equipment does not prevent exposure to penetrating forms of radiation from radioactive material nor did it prevent skin contamination for those who stepped into puddles of contaminated water that then entered their boots. A helmet was also required depending on the operation. All personal protective equipment was disposable and was stored in the restricted area. A Geiger counter was used at the gate to the base station to measure and strictly control the radiation levels of each individual.

The Ministry of Health, Labour and Welfare required regular health examinations for any worker who had been exposed to $100 \mathrm{mSv}$ or who had worked at the site for over a month on 25 April. These examinations included checks on any adverse health conditions, skin examinations, and white and red blood cell counts (blood tests were omitted at the physician's discretion in case of $<100 \mathrm{mSv}$ exposure) every week for 3 months after finishing operations at the site up to 16 December 2011. The Ministry of Health, Labour and Welfare, Japan, has established a system for following up the workers at Fukushima Dai-ichi NPP to identify any diseases as early as possible and to determine the health risks caused by radiation exposure. ${ }^{8}$ The ministry ordered TEPCO not to allow workers with a cumulative exposure of $200 \mathrm{mSv}$ to work at the site after June $13 .^{8}$

Potassium iodide (KI), which blocks uptake of radioactive iodine by the thyroid and helps prevent thyroid cancer due to internal exposure, was prescribed for workers after physicians interviewed them regarding iodine hypersensitivity and any previous thyroid conditions. ${ }^{12}$ Taking KI does carry the risk of hypothyroidism, which increases with age, and KI has limited ability to prevent radiation-induced thyroid cancer in individuals aged over $40 .{ }^{12}$ According to the Nuclear Safety Commission of Japan, workers who are exposed to an equivalent dose of $100 \mathrm{mSv}$ for the thyroid should take a $100 \mathrm{mg}$ KI tablet on the first day and a $50 \mathrm{mg}$ KI tablet every day thereafter when operations are being carried out; the limit of continuous prescription should be 14 days. ${ }^{13}$ The guidelines call for workers aged over 40 to take KI tablets in the case of high exposure to radiation, subject to the worker's assent.

\section{Heat}

To prevent heat stroke, administrative and engineering controls, and personal protection were implemented. In terms of administrative controls, the government prohibited TEPCO from operating from 14:00 to 17:00, from June 27 to August 31 when the risk of heat stroke is relatively higher, which resulted in operations being implemented from early morning to 14:00. ${ }^{14}$ Workers at the site were allowed to work several shifts, with an hour's work and a 40-min break (the latter included removing protective clothing after checking for radioactive contamination, resting and putting the protective clothing on again prior to work). This work to rest ratio exceeded the screening criteria for TLV® of the American Conference of Governmental Industrial Hygienists and required the implementation of job-specific controls. ${ }^{11}$ The work shift could not be shortened because it took at least $1 \mathrm{~h}$ to carry out operations, including going to and returning from the work site to the command station. Because of this longer work shift, workers had to monitor their own health condition every $30 \mathrm{~min}$, as well as monitor each other and identify coworkers who appeared to be showing signs of heat stroke. Workers were also encouraged to take a rest if they felt sick. An emergency room with volunteer doctors from various medical schools and hospitals in Japan who specialise in emergency medicine was set up at the site to respond to heat stroke and injuries. The doctors responded immediately once injury occurred and referred severe cases to the designated secondary or tertiary hospitals with facilities for protection from radiation with transport by ambulance or helicopter. At daily meetings 
held with the workers at 9:00 and 18:00, the top executives emphasised the importance of preventing heat stroke and injuries.

With regard to engineering controls, an air conditioned rest room was installed near the operation site for the workers' convenience. In terms of personal protection, workers wore a cool vest under the Tyvek $\AA$ coverall, were required to drink a $500 \mathrm{ml}$ oral rehydration solution before the $1-\mathrm{h}$ shift and drank 200-500 ml after each 1-h shift. Health requirements for working at the site were high, and prescreening of individuals' fitness for work, especially for those with chronic conditions susceptible to heat, was necessary. Forty-six workers were reported to consulting physicians because of signs of heat stroke from March to October 2011. All of them had mild to moderate heat stroke and there have been no fatal cases of heat stroke.

\section{Stress}

Occupational health physicians and nurses provided mental health checks and consultations for workers. The Ministry of Health, Labour and Welfare, Japan, also provided toll-free telephone mental health services. However, primary prevention of stress including the improvement of accommodations of workers could not be provided optimally.

\section{Machine operation and manual handling}

Efforts to ensure safety at the site were the top priority and were planned and implemented carefully. From the viewpoint of occupational health, prescreening of individuals' fitness for work, especially for those who have a history of seizure, was important.

\section{CONCLUSIONS}

The major occupational health hazards at Fukushima Dai-ichi NPP until cold shutdown were radiation exposure, heat, stress, and machine operation and manual handling. Even in these unusual conditions, based on accumulated evidence and lessons learnt from the past, various measures were implemented to minimise the risks to workers. However, because of the adverse situation, stress management, including providing better living conditions, was not optimal, even though occupational health staff recognises its importance. Decommissioning of the
Fukushima Dai-ichi NPP will take 30-40 years and occupational health should continue to be the top priority.

Acknowledgements The authors sincerely appreciate the workers at Fukushima Dai-ichi NPP.

Contributors KW and TY conceived the manuscript. All the authors participated in the discussion.

Competing interests None.

Provenance and peer review Not commissioned; externally peer reviewed.

\section{REFERENCES}

1. National Police Agency of Japan. Damage Situation and Police Countermeasures in Tohoku Associated with the 2011 the Pacific Ocean Earthquake. 2011. http://www. npa.go.jp/archive/keibi/biki/higaijokyo_e.pdf

2. Christodouleas JP, Forrest RD, Ainsley CG, et al. Short-term and long-term health risks of nuclear-power-plant accidents. N Engl J Med 2011;364:2334-41.

3. Ministry of Economy, Trade and Industry. Roadmap for Immediate Actions for the Verification of and Restoration from the Accident at Fukushima Dai-ichi Nucler Power Station. Japan. 2011. http://www.meti.go.jp/english/earthquake/nuclear/roadmap/ pdf/110517roadmap NPS.pdf (accessed 8 Feb 2012)

4. International Atomic Energy Agency. Report of Japanese Government to IAEA Ministerial Conference on Nuclear Safety-Accident at TEPCO's Fukushima Nuclear Power Stations. 2011. http://www.iaea.org/newscenter/focus/fukushima/japanreport/ (accessed 13 Nov 2011).

5. Tokyo Electric Power Company. Assessment of Radiation Exposure of Workers at Fukushima Dai-ichi Nucler Power Plant (In Japanese). 2011. http://www.tepco.co.jp/ cc/press/betu11 j/images/111031e.pdf (accessed 30 Jan 2012).

6. Kondo M, Honda Y, Ono M. Growing concern about heatstroke this summer in Japan after Fukushima nuclear disaster. Environ Health Prev Med 2011;16:279-80.

7. Kalef-Ezra JA, Valakis ST, Soupsanas T. A high-sensitivity multidetector whole-body counter. Radiat Prot Dosimetry 2011;144:415-18.

8. Ministry of Health Labour and Welfare. Timelines of the Government Responding to Protecting Workers at Fukushima Dai-ichi Nuclear Power Plant (In Japanese). 2011. http://www.mhlw.go.jp/shinsai jouhou/keii.html (accessed 20 Jan 2012).

9. United Nations Scientific Committee on the Effects of Atomic Radiation. Sources and Effects of lonizing Radiation. 2008. http://www.unscear.org/docs/ reports/2008/11-80076 Report 2008 Annex D.pdf

10. National Institute for Environmental Studies. Information for Preventing Heat Stroke. 2011. http://www.nies.go.jp/health/HeatStroke/est/dl.html

11. ACGIH. Threshold Limit Values for Chemical Substances and Physical Agents. Cincinnati, OH, USA: American Conference of Government Industrial Hygienists, 2006.

12. World Health Organization. Use of Potassium lodide for Thyroid Protection During Nuclear or Radiological Emergencies. 2011. http://www.who.int/ionizing_radiation/ pub_meet/tech_briefings/potassium_iodide/en/index.html (accessed 17 Nov 2011)

13. Nuclear Safety Commission of Japan. Technical Advice for Prescribing Potassium lodide for Workers at Fukushima Dai-ichi Nucler Power Plant. 2011. http://www.nsc. go.jp/ad/pdf/20110407 2.pdf (accessed 12 Nov 2011).

14. Ministry of Health Labour and Welfare. Enforced Prevention Heat Stroke Fukushima Dai-ichi Nucler Power Plant. 2011. http://www.mhlw.go.jp/stf/houdou/ 2rg852000001f4ob.html 